\title{
Energy balance comparison of small unmanned vehicle equipped with electric and hybrid propulsion system
}

\begin{abstract}
Article presents comparison of the energetic balance of vehicle powertrain - pure electric vehicle and vehicle equipped with electric hybrid power transmission. Society is more and more often persuaded to buy electric cars as an environmentally friendly solution because they have opinion of ecological vehicles. Electrification in military applications is also widely considered, especially in case of small to medium UGV's such as wide range of robotic systems introduced to the milatary operations. The article presents the problems of comparing the efficiency and others parameters such as the range of a two presented powertrains. The research was carried out on an small unmanned land platform equipped with a hybrid propulsion system supplied as standard with Diesel power generator and electrically only powered. Energy used for charging of the battery, from tank-to-wheel, was calculated. This also enables to calculate total efficiency of electric and hybrid power transmission. By calculating different capacity of battery and power of generator, it is possible to determine the vehicle range.
\end{abstract}

Key words: hybrid propulsion, UGV, electric propulsion, energy balance

\section{Introduction}

Unmanned vehicles can patrol area, measure contamination level of the environment, deliver supplies, operate as a movable fire stand or help to evacuate wounded from danger area (Fig.1a, 1b) [12]. Military or civil use of those vehicles is more often introduced [5]. Especially, their use in military conflict region can have impact on safety of soldiers attending in this conflict.

a)

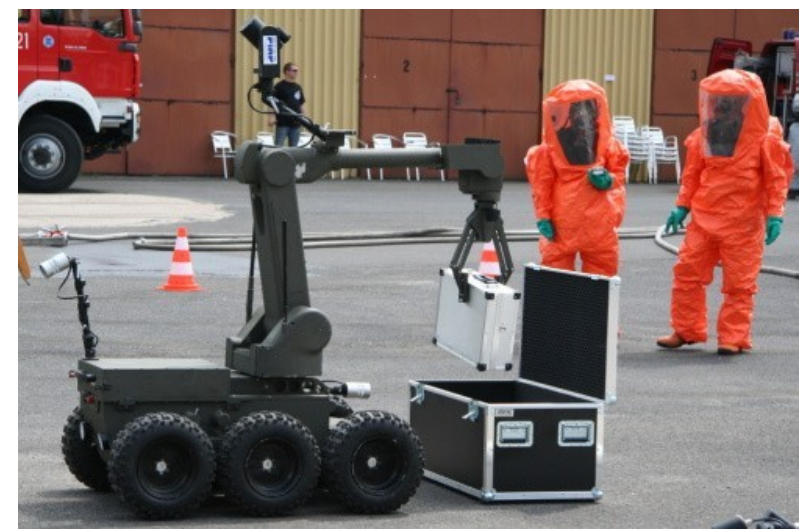

b)

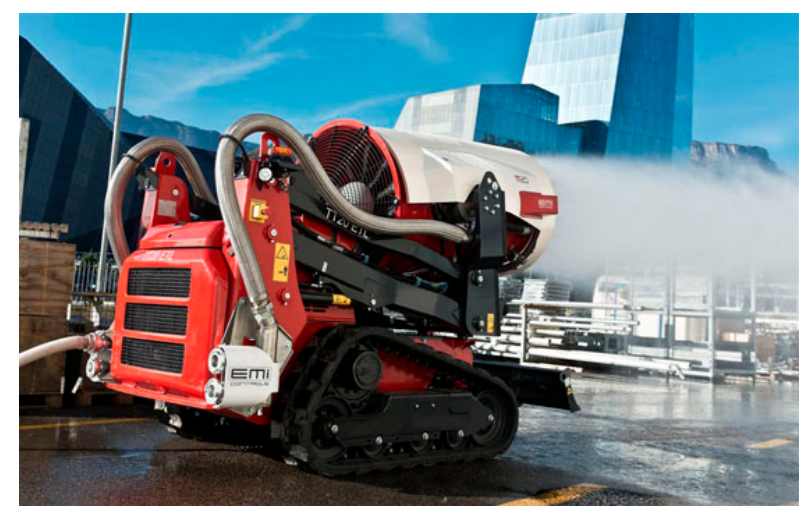

Fig. 1. Example of use UGV vehicles: a) operating in contaminated area [14], b) firefighting unmanned system [15]

To comply its tasks, it is necessary to ensure quiet relocation and long range or long operating time in conflict area without support. Those requirements can be met by vehicles equipped with electric or hybrid drive - power transmission system with electric engines enable to quiet operate in endangered area [7, 8]. For such operations, series hybrid transmission ant it's variants are become more and more often present is UGVs and other vehicles. High efficiency of electric engines cause slight thermal trace, improve undetectability by enemy forces. Electric vehicles are quite simple in use and in construction. Mostly they propulsion system consist of battery, electric engine with controller. This simplicity is important in many operations but because of small capacity of the battery, still insufficient volumetric and mass factors and it's ability of caught fire. Battery operated vehicles disadvantages turn many researchers to give attention to hybrid propulsion, especially series with small power generator. Vehicles, equipped with power generator, enable to load battery and increase range and operation time without need of fast come back to the base [11]. Because fuel deliveries can be interrupted by different reasons, for instance in warfare conditions, or others aspects such as economical or ecological, this solution can be useful in military vehicles. Such construction can use different fuels besides Diesel. For example, vehicles could use other fuels such as F-34 which is introduced as a unified battlefield fuel [2] or different mixtures of fuels that will work with CI engines. Because mentioned fuels have different parameters, they will impact to the engine parameters. Requirements for unmanned vehicles, especially their power transmission, is not easy to achieve. Costs of production and total mass of vehicle are contradictory to use cheap but heavy electrochemical batteries. Long range require use of high energy density of power sources but combustion engines are noisy and emitting a lot of thermal radiation (easy to detect). Other aspects are for example: compatibility with existing infrastructure (combustion engines), fast recharging (combustion engines) $[1,6]$ etc. Most foredesigns exclude of use one or other solution, other technology. It is necessary to take under consideration a tank-towheel (and battery-to-wheel) energy balance in efficiency and vehicle's mobility point of view. 


\section{Vehicle's investigated power transmission}

Power transmissions of the investigated vehicles came from small unmanned ground vehicle (Fig. 2a) of total mass $500 \mathrm{~kg}, \mathrm{LiFePO}_{4}$ battery pack and six independent driving modules which were assembled with electric engine, inverter and transmission gears, wheel and shock absorber. Each module was connected to the 48 VDC battery pack (Table 1).

a)

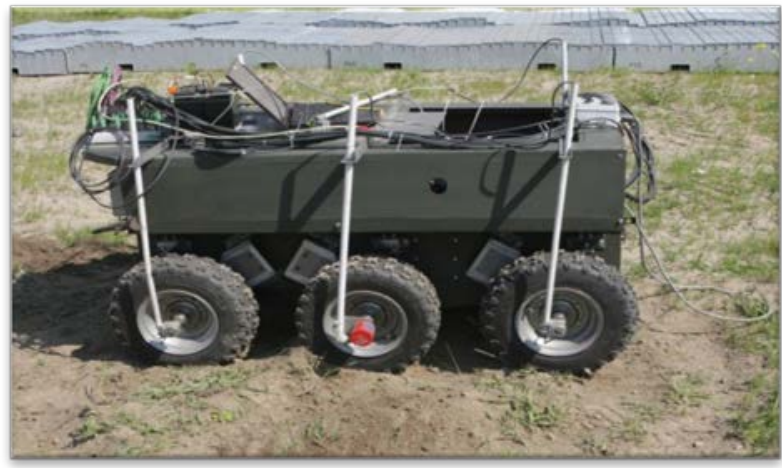

b)

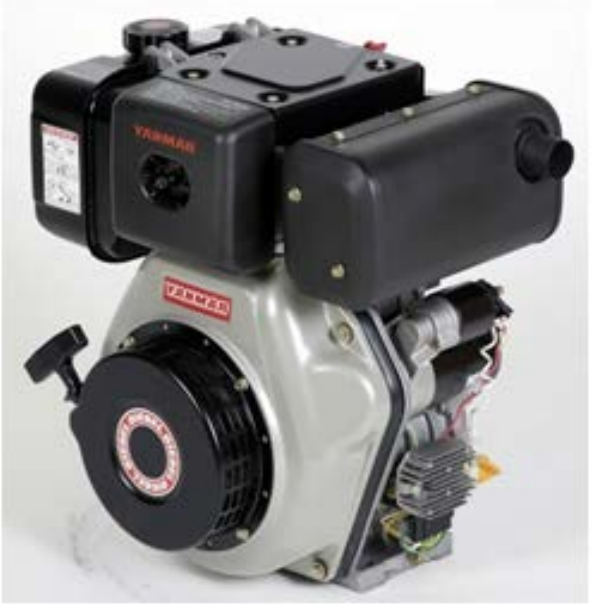

Fig. 2. a) investigated UGV with power transmission during tests, b) Diesel engine for vehicle's power generator [16]

Power transmission system was installed inside the hull of the vehicle. Vehicle itself is more widely described in [3, $9,10]$. For tests two variants of vehicle's powertrain were examined, electric and with small Diesel power generator (Fig. 2b). In result, second variant of power propulsion system was designed as a serial hybrid called range extender or REx. It was assumed, that for electric propulsion, battery will have higher capacity, equal to the mass of power generator (Fig. 3). Operating range of unmanned ground vehicle and its power transmission systems were then examined.

Table 1. Vehicle's power transmissions main components parameters

\begin{tabular}{|l|c|c|}
\hline Component & Electric propulsion & Hybrid propulsion \\
\hline Electric engine & $6 \times 2.8 \mathrm{~kW}$, PMS & $6 \times 2.8 \mathrm{~kW}$, PMS \\
\hline Battery & 210 Ah@48 VDC & 70 Ah@48 VDC \\
\hline Power generator & - & $5.5 \mathrm{kVA}$ \\
\hline Fuel tank & - & $5 \mathrm{dm}^{3}$ \\
\hline
\end{tabular}

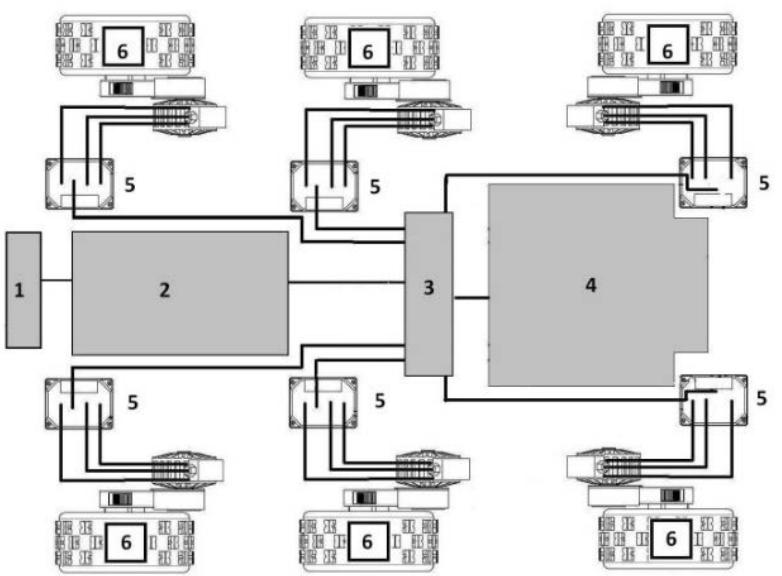

Fig. 3. Schematic connections of hybrid power propulsion: 1) steering system, 2) power generator, 3) junction box, 4) battery, 5) inverters, 6) driving modules with electric engines, wheels and gears

\section{Laboratory testing of electric and hybrid power transmission}

The main goal of laboratory tests of electric and hybrid power transmission system of UGV was to determine energy balance of this systems after integration and installation on a vehicle hull. Test was held on stands belonging to combustion engines laboratory of Military University of Technology. Range of the tests included:

- measurements of lithium $\mathrm{LiFePO}_{4}$ battery charging and discharging efficiency,

- measurements of power generator efficiency,

- measurements of electric engines efficiency of vehicle,

- measurements of power transmission efficiency.

Based on efficiency of particular elements of power transmission systems and fuel calorific value, fuel consumption, energetic balance of unmanned vehicle was calculated and determined.

\subsection{Test stands}

During tests, five stands were used:

- $\mathrm{LiFePO}_{4}$ battery charging test stand (Fig. 4). A stand for measuring charging characteristics of battery while charging process.

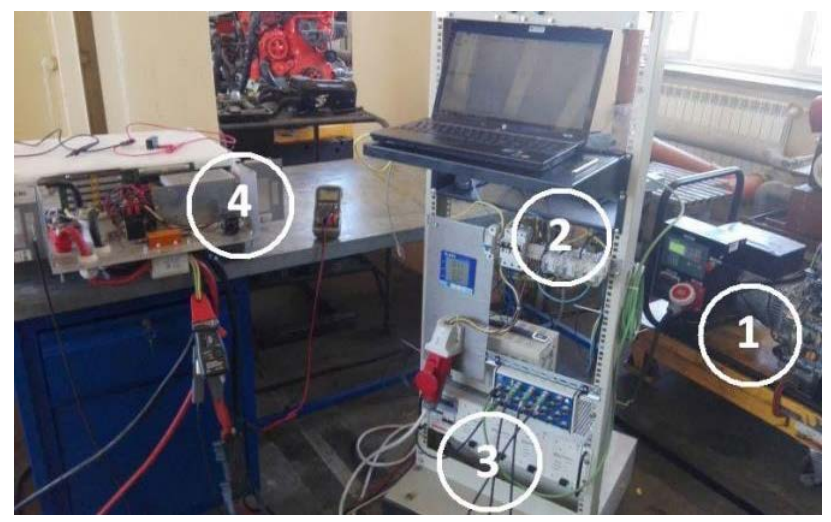

Fig. 4 Charging test stand: 1 - power generator, 2 - current-voltage parameters acquisition system, 3 - constant-current power station, 4 - battery

- $\mathrm{LiFePO}_{4}$ battery discharging stand (Fig. 5). Test stand for measuring discharging parameters of battery enable to set discharging characteristics under different loads. 
For battery load, water resistor was build. This type of resistor enable fast and simple operation of resistor, by submerse metal plates of resistor in wear. Discharging current could be increased by increasing number of metal plates or water additives. Battery was equipped with voltage sensors.

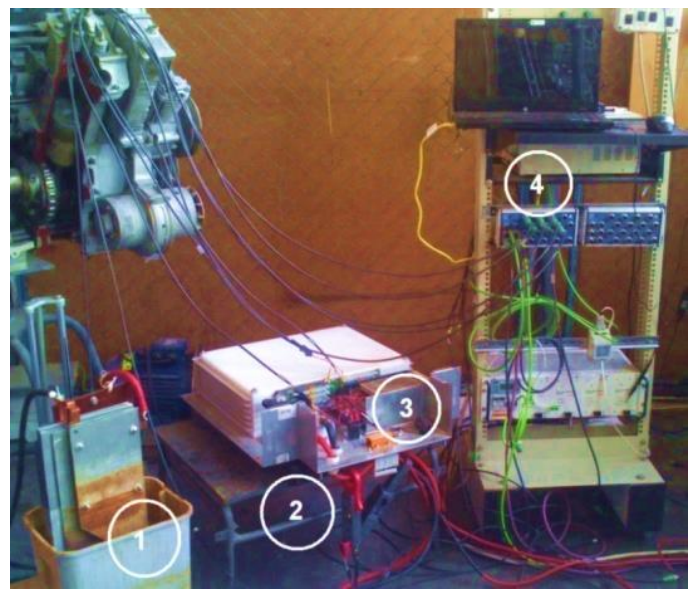

Fig. 5. Battery discharging test stand: 1) water resistor, 2) current clamps, 3) battery with voltage sensors, 4) acquisition computer

- electric engines test stand (Fig. 6). On this stand, changes of the engine torque were measured if function of engine speed. Investigated engine was mounted on a dyno stand and connected through the clutch with dyno. Engine mounted on the stand worked as a dynamometer. On his housing, force meter was mounted and force was measured. Examined engine was connected to the inverter and inverter was connected to the power supply. Current and voltage sensors were connected to the acquisition card and computer. Speed of the engine was measured by speed encoder connected to the acquisition card.

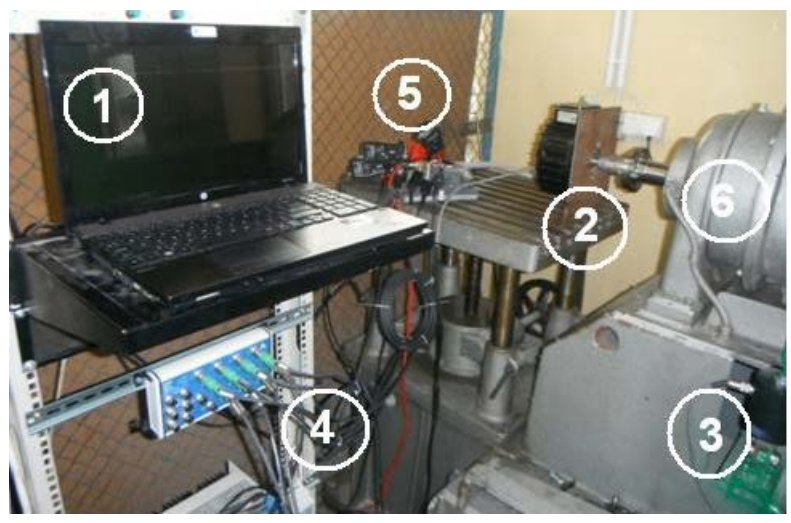

Fig. 6. Electric engines test stand: 1) acquisition equipment 2) electric engine, 3) force sensor, 4) acquisition hardware, 5) current inverter, 6) electric engine of the dyno stand

- power generator characteristic determination test stand. This stand was equipped in similar instrumentation as during battery charging, but with extra load for generator. Load characteristic of the power generator was determined, after connecting load to the generator.
- power transmission internal resistances test stand (Fig. 7). Measurements of internal resistance of the power transmission was made after lifting vehicle by warehouse truck to loose contact between wheels and ground. Speed was increased in stages to the maximum and then decreased to the wheels stop. Rotation velocity of the wheels was set by voltmeters indication, placed next to the controller (Fig. 8).

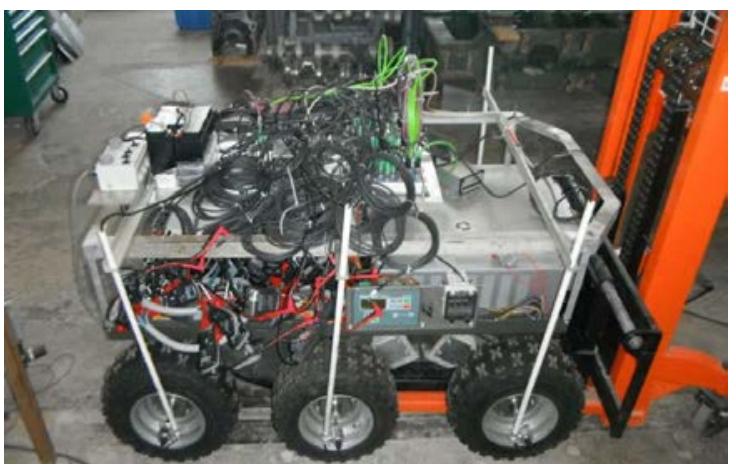

Fig. 7. Internal resistance measurements

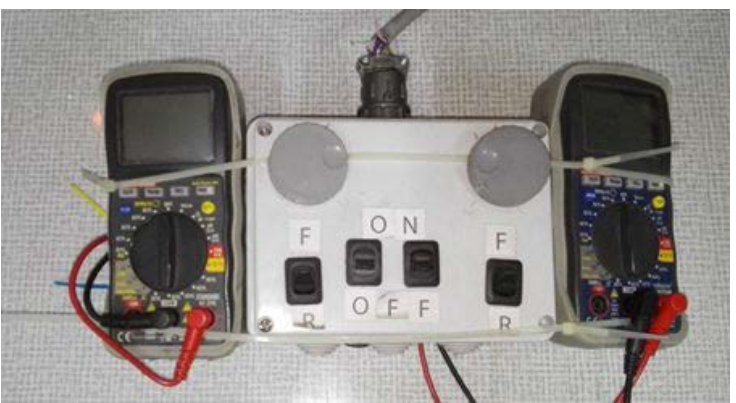

Fig. 8. Connected voltmeters for speed verification

\section{Energetic balance comparison of the power transmissions}

To determine energetic balance, calorific value of the Diesel oil was determined as $43 \mathrm{MJ} / \mathrm{kg}$. Total energy of a single charging process of the battery was equal to $50.282 \mathrm{MJ} / \mathrm{kg}$, and came from fuel of $1.15 \mathrm{~kg}$. Energy from fuel powered generator and charged battery with power $10.555 \mathrm{MJ} / \mathrm{kg}$, after sweep to electric energy, this mean the efficiency is equal to $21 \%$ with specific fuel consumption of $300 \mathrm{~g} / \mathrm{kWh}$ (Fig. 9), what is satisfied value in small Diesel engines.

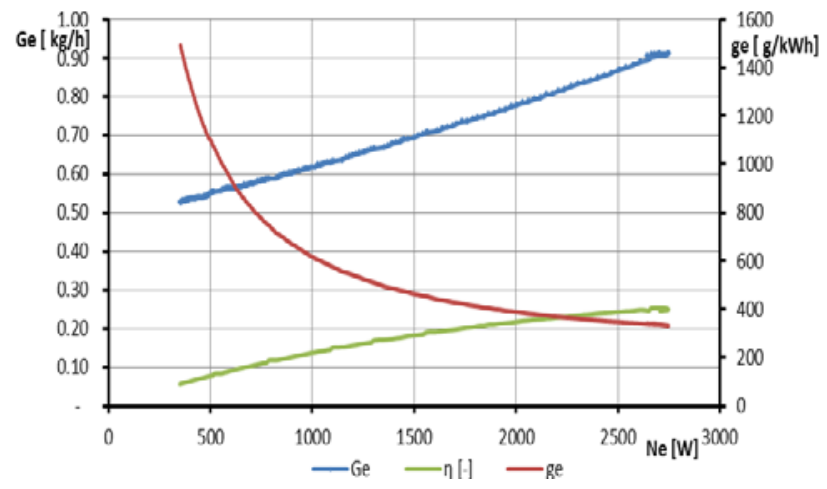

Fig. 9. Load characteristic of power generator 
Charging the battery need 9.65 MJ of energy (Fig. 10). During discharging process, the energy level reaches 9.0 MJ of energy. Calculations leads to the assumption that such amount of energy should provide power for travelling distance of $16 \mathrm{~km}$ with speed of $5 \mathrm{~km} / \mathrm{h}$. Fuel tank capacity enable to charge the battery more than three times to its full capacity. This enables to reach distance over $65 \mathrm{~km}$ with fully charged battery at the beginning.

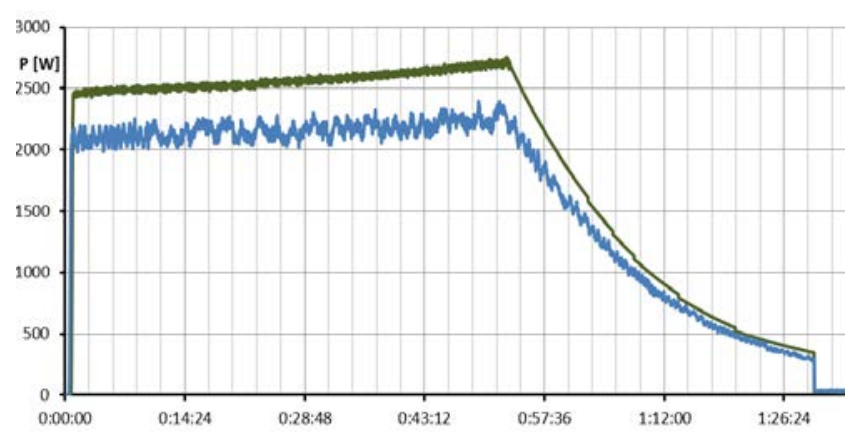

Fig. 10. Charging power of the battery (blue line) and electric power of the generator (green line)

Theoretical efficiency of each vehicle's module (from engine to wheel) should reach ca. $90 \%$. Because of the quality of components (the vehicle is technology demonstrator) efficiency of driving modules reaches $75 \%$ averages.

Efficiency of energy conversion from chemical energy of fuel to the energy converted for wheels powering is quite small. It is caused mostly by low efficiency of combustion engine that power the generator. It is small, naturally aspirated one cylinder compressed ignition engine. His internal resistance is big if compare to power produced. Efficiency of power transmission powered from battery is bigger and reach $70 \%$. Total efficiency of hybrid power transmission, when combustion engine was turned on, reaches $13.6 \%$ (from tank to the wheel). It is important to know, that power generator can work temporary, when its need and do not cover all energetic needs of vehicle. That means total efficiency must be seen partly as a efficiency of the hybrid with power generator and partly as a electric transmission.

Power consumed by the vehicle in different road conditions (speed, quality and type of the surface), and parameters of the power transmission, enable to determine range of the vehicle and speed of the vehicle with power generator.

Based on results of charging and discharging of the hybrid power transmission battery, measurements of internal resistances, energetic parameters of the power transmission and energetic balance were determined. Based on that calculation, it was possible to determine range of the vehicle. During calculations, internal resistances were took into account. Results were presented in Table 2.
Table 2. Efficiency of power transmission subassemblies

\begin{tabular}{|l|c|c|}
\hline Component & Energy & Average efficiency \\
\hline Fuel & $50.28 \mathrm{MJ}$ & - \\
\hline Battery (hybrid) & $9 \mathrm{MJ}$ & $94 \%$ \\
\hline Battery (electric) & $26.8 \mathrm{MJ}$ & $95 \%$ \\
\hline Power generator & $10.56 \mathrm{MJ}$ & $21 \%$ \\
\hline \multicolumn{2}{|c|}{ Electric average efficiency } & $70 \%$ \\
\hline \multicolumn{2}{|c|}{ Hybrid average efficiency } & $13.6 \%$ \\
\hline
\end{tabular}

Vehicle powered only from the power generator, enable to charge the battery in time of 93 minutes. During driving this time is elongated, because some part of the energy is consumed by the wheels of the moving vehicle. This time can be elongated or if road resistance will be higher than power generated, battery will never be fully charged. In case of totally discharged or damaged battery, maximum vehicle speed is about $20 \mathrm{~km} / \mathrm{h}$, when moving on a concrete or asphalt, without charging.

Efficiency of pure electric transmission is higher than hybrid, but if battery mass will be equal to the mass of battery and power generator, traveling distance of such vehicle will be smaller ca $25 \%$. It is important to know that increasing the mass (and volume) of the battery will cause mass of vehicle's components increase (up to $40 \%$ of battery mass) [13].

\section{Conclusions}

1. Laboratory tests of power transmission subassemblies enable verification of their characteristics and parameters. Battery parameters measurements enable to estimate vehicle's range in different driving modes.

2. Energetic parameters were set of two investigated power transmissions. Efficiency of the energy consumption in pure electric drive was ca. $70 \%$. A set of batteries with mass equal to the mass of the power generator enable to drive distance of ca. of $45 \mathrm{~km}$ with speed of $5 \mathrm{~km} / \mathrm{h}$. In hybrid power transmission, efficiency with working power generator drops down up to $13.6 \%$. Fuel tank capacity enable to charge the battery more than three times to its full capacity. This enables to travel distance over $65 \mathrm{~km}$ on a flat surface.

3. During one charging cycle (93 minutes) generator used $1150 \mathrm{~g}$ of fuel, which means, that extra $3.5 \mathrm{~kg}$ of fuel can double the traveling distance in respect to the extra 180 $\mathrm{kg}$ of battery (plus ca. $40 \%$ mass of battery for strengthened vehicle structure).

4. Energetic balance efficiency of pure electric power transmission is much higher (ca. 70\%) than efficiency of serial hybrid transmission with turned on power generator (ca. 13\%), but travelling distance of hybrid transmission vehicle was ca. $25 \%$ higher.

\section{Nomenclature}

$\begin{array}{ll}\text { BEV } & \text { battery elctric vehicle } \\ \text { CI } & \text { compresed ignition } \\ \text { CNG } & \text { compressed natural gas } \\ \mathrm{G}_{\mathrm{e}} & \text { fuel consumption }[\mathrm{kg} / \mathrm{h}] \\ \mathrm{g}_{\mathrm{e}} & \text { specific fuel consumption }[\mathrm{g} / \mathrm{kWh}] \\ \mathrm{HEV} & \text { hybrid electric vehicle }\end{array}$

$\mathrm{LiFePO}_{4}$ lithium-iron phosphate battery

PMS Permanent Magnets Synchronous electric engine

REx Range Extender electric vehicle

UGV Unmanned Ground Vehicle

VDC Direc Current Voltage 


\section{Bibliography}

[1] FLUDER, K., PIELECHA, I., CIEŚLIK, W. The impact of drive mode of a hybrid drive system on the energy flow indicators in the RDE test. Combustion Engines. 2018, 175(4),18-25. https://doi.org/10.19206/CE-2018-403

[2] KARCZEWSKI, M., SZCZECH, L. Influence of the F-34 unified battlefield fuel with bio components on usable parameters of the IC engine. Eksploatacja i Niezawodność Maintenance and Reliability. 2016, 8(3), 358-366. https://doi.org/10.17531/ein.2016.3.6

[3] KARCZEWSKI, M., SZCZĘCH, L., POLAK, F. Energetic balance of unmanned ground vehicle hybrid power transmission. Journal of KONES Powertrain and Transport. 2018, 25(2). https://doi.org/10.2478/kones-2019-0094

[4] KARCZEWSKI, M., SZCZĘCH, L., POLAK, F. Energetic balance of unmanned ground vehicle. Journal of KONES Powertrain and Transport. 2019, 25(2). https://doi.org/10.5604/01.3001.0012.2797

[5] LOPEZ, R., DARPA Develops tactical robots for dirty and dangerous missions. unmanned systems. 2001, 12-13.

[6] PIELECHA, I., CIEŚLIK, W., FLUDER, K. Analysis of energy management strategies for hybrid electric vehicles in urban driving conditions. Combustion Engines. 2018, 173(2), 14-18. https://doi.org/10.19206/CE-2018-203

[7] POLAK, F., WALENTYNOWICZ, J. Problemy doboru zespołów układu napędowego do małego taktycznego pojazdu bezzałogowego. Journal of KONES Powertrain and Transport. 2007, 14(4), 343-350.
[8] POLAK, F., SZCZECH, L. Driving module of the unmanned vehicle. Journal of KONES Powertrain and Transport. 2011, 18(1).

[9] POLAK, F., SZCZECCH, L., WALENTYNOWICZ, J. Napęd lekkiej platformy bezzałogowej do działań w terenie zurbanizowanym. Technologie podwójnego zastosowania, Wybrane Technologie Wojskowej Akademii Technicznej (red.). Najgebauera, A. WAT, Warszawa 2012.

[10] POLAK, F., SZCZECH, L. Propulsion module for unmanned vehicle. Journal of KONES Powertrain and Transport. 2011, 18(1).

[11] REDELBACH, M., ÖZDEMIR, E.D. Optimizing battery sizes of plug-in hybrid and extended range electric vehicles for different user types. Energy Policy. 2014, 73, 158-168. https://doi.org/10.1016/j.enpol.2014.05.052

[12] RYBAK, P., WYSOCKI, J., HRYCIÓW, Z. et al. Experimental research on identifying data for modelling special purpose vehicles. Journal of KONES Powertrain and Transport. 2017, 24(3). https://doi.org/10.5604/01.3001.0010.3086

[13] SANDY, T.C.E. Sustainable transportation options for the $21^{\text {st }}$ century and beyond. Appendix A: Range limitations of battery electric vehicles. Springer International Publishing. Switzerland 2015. https://doi.org/10.1007/978-3-319-16832-6

[14] www.altair.com.pl access: 2015.05.17

[15] https://www.fireapparatusmagazine.com/2014/06/24/pg06/\#gref access: 2020.04.14

[16] https://www.yanmar.com/us/ access: 2020.05.21

Filip Polak, DEng. - Faculty of Mechanical Engineering, Military University of Technology.

e-mail: filip.polak@wat.edu.pl 